\title{
Entangled in the Mangroves: Negotiating Anthropocene Heritage in the Terrestrial/Marine Interzone of an Iconic Harbour City
}

\author{
Philip Hayward
}

The Anthropocene is a multifaceted phenomenon. One aspect that is often overlooked is that it constitutes a heritage. Heritage is itself a complex notion that manifests in different ways depending on subjective and/or ideological positions taken towards it. The picture is further complicated if we attempt to take non-, pre- or post-human perspectives into account. This paper attempts to unravel various aspects of Anthropocene heritage through a case study of a small area of Sydney's inner harbour. The area concerned is one explored and experienced on a daily basis by the author as a resident engaged in auto-ethnographic contemplation of the locale and aware of the contradictions of living in such an urban space whilst advocating and campaigning for various Green concerns. The paper thereby addresses the entanglement of human and nonhuman, urban and ecological ways of living, and various senses and perceptions of space in a particular terrestrial/marine interzone. More particularly, it examines the manner in which mangroves are an active agent and key marker of space within this area.

Keywords: mangrove; harbour; land reclamation; terrestrial/marine interzone; Sydney; Burns Bay

\section{Introduction}

The Anthropocene is frequently cast as an unmitigated disaster for both the planet (understood as an holistic assemblage of organic and inorganic elements) and for the species, ourselves, that caused this disaster. Perspectives on this disaster vary from those held by bodies such as the Voluntary Extinction Movement, who advocate the removal of humans from the planet as the only solution, to those who advocate deep ecological design to slow the pace of the Anthropocene and create more sustainable ways of living (e.g. Naess 1989; McLaughlin 1993 ; Gibson, Rose and Fincher 2015). The urgency of the global climate crisis is evident to many and has inspired much debate and action. As a modest but persistent Green activist, I have campaigned against prominent climate change deniers in Australian government and have also spent over two decades of regular engagement in rainforest restoration in the far north-east of the Australian state of New South Wales. I see the two activities as complementary in that the political macro-level gives context to local-level material action while the latter grounds the former. But operating between these two polarities has also brought home to me the extent to which a substantial area of human experience - and of reflection on that experience - has been absent from considerations of engagement with the

University of Technology Sydney, AU

prhshima@gmail.com
Anthropocene. The experience I refer to is the everyday interaction we have with mixed natural and human engineered environments and artefacts. Such interactions are key to experience of the epoch and can give rise to reflections that can inform both philosophy and activism.

I should acknowledge at this point that I am writing this paper as someone who has lived in eastern Australia for the majority of their adult life. Each country and region has its own history of Green activism whose successes and failures shape the perceptions of campaigners and opponents alike. This is especially the case in Australia, which has seen particular campaigns, such as that mobilised in 1978-83 to save the Franklin River in Tasmania, become iconic to the global Green movement. The Franklin River campaign was motivated by and successful in preserving an area commonly characterised as 'wilderness,' in that its habitat and species appear substantially unmodified by human agency (Branagan 2020). Such wildernesses have come to be regarded as important ecological assets in a manner that draws on Western philosophical and aesthetic paradigms of 'the wild' (Godfrey-Smith 1979; Nelson and Vucetich 2013) but sit uneasily with Indigenous people's prolonged and profound inter-relation with and impact on such locales (Langton 1996; Lee 2018). Closer to my geographical home, the campaign to save the seven-acre waterside area known as Kelly's Bush in the Sydney suburb of Hunters Hill was distinguished by the collaboration of local residents and trades unions who opposed developers. This coalition eventually pressured the NSW 
state government into heritage listing the area in 1983 (Shaw 1996). The Kelly's Bush campaign indicated the strength of Sydney residents' concern about protecting bushland areas, particularly those along the Harbour's extended waterfront, and influenced many local councils to exclude a number of these areas from development. The principal difference between the Franklin River and Kelly's Bush was that - for all that the latter retained a variety of endemic Sydney species - it was hardly pristine. Indeed, Kelly's Bush had been modified in various ways by timber extraction and other human interventions since the 1890s, when a metal smelting plant was set up there that operated until 1967. The area's environmental value resided in the manner in which land surrounding the plant that had been left relatively untended and undeveloped. Since its heritage listing it has been maintained to minimise the spread of invasive species and allow it to 'rewild,' while allowing public access to and through it.

Rewilding is an approach to regenerating ecosystems that have been disturbed by various Anthropocene phenomena (Monbiot 2013). Rewilding takes various forms from precisely targeted interventions, such as the reintroduction of beavers to southwest England in 2015 or of Tasmanian devils to continental Australia in 2020, to what is often described as 'passive rewilding' (Morel, Barbe, Jung et al. 2019). The latter is a practice that allows local species to return and reassert themselves in particular areas, usually with some assistance in removing or reducing invasive or antagonistic species and/or fencing areas to allow them to flourish. In many contexts, and particularly urban ones where areas of un-built-upon and/or disused areas of land are small and often disconnected, rewilding occurs as a mixture of planned land management and of neglect (which may be considered benign or otherwise depending on one's motivations and/or perspective). By virtue of its being deemed necessary, such rewilding occurs in urban landscapes that both have a heritage of disturbance and development (in terms of resource use and construction) and, in many cases, of infrastructural decay, where buildings, technologies, access routes etc. deteriorate and allow various species to move into areas previously maintained to prioritise human activities. As Lorimer (2015) has identified, while the notion of a preAnthropocene/prelapsarian 'wild,' natural world that might be recoverable is key to the concept and operation of re-wilding, the global reach of the Anthropocene means that such idealised past states are unattainable. Re-wilding instead operates as a particular type of Anthropocene phenomenon, a conscious, ecologically-informed human intervention into disturbed environments that differs from previous interventions in aiming to create new, wilder niches across the planet.

The notion of heritage merits consideration here. A considerable body of discourse and characterisation has developed with regard to heritage, most notably promulgated by UNESCO (the United Nations Educational, Scientific and Cultural Organization). UNESCO's primary definition of 'world heritage' is relatively straightforward - as 'our legacy from the past, what we live with today and what we pass on to future generations' (UNESCO, n.d.).
The sentence following that definition separates heritage into two types, 'cultural' and 'natural,' and identifies both as 'irreplaceable sources of life and inspiration' (ibid.). This is more complex. Characterising heritage as 'irreplaceable' is relatively uncontentious if we overlook the way perspectives on our past vary depending on contemporary belief systems and/or scientific knowledge. These can replace or counter one perception on the past with another. The characterisation of heritage as a source of 'life' and 'inspiration' is even fuzzier, presumably meaning that our current society, cultures and technologies are the necessary result of the history of human achievement (which is taken to inspire 'us' to continue with our multiple activities). It is also crucial to recognise that in the Anthropocene context in which UNESCO's discourse engines operate 'natural' heritage is not something distinct from human heritage but, rather, something fundamentally produced by it.

Questions about who the 'us' is and whose and what 'legacy' is passed on to future generations are particularly pertinent in colonised and post-colonised societies. These are contexts in which colonising agencies and/or the local elites that influence national perceptions of and policies concerning heritage can propagate an agenda that is exterior to the societies concerned. This is problematic on several levels. First, notions of cultural and natural heritage are hardly neutral. Cultural heritage, while seemingly wide and inclusive, has been codified into particular sets of practices and entities by Western agencies using Western perceptions and paradigms - as exemplified by the UNESCO document 'What is Cultural Heritage?' (n.d.). Similarly, natural heritage proceeds on the assumption of there being a 'nature' that is innately pre-human and/or fundamentally unaffected by human factors (at least at some notional moment in the imaginable historical past). Such perspectives were notably articulated with regard to Australia and the tensions between its Indigenous and settler cultures by Australian archaeologist and heritage scholar Laurajane Smith. Her 2006 volume Uses of Heritage stressed that heritage, especially in settler contexts, is processual - open to contestation, revision and multi-perspectivity - rather than an inventory of things that requires maintenance and valourisation. And further, that hegemonic notions of heritage and entities perceived to embody heritage are the products of discourse rather being than objective entities that 'possess' heritage. Equally, Indigenous cultures produce heritage through repetition, reinscription and the development of perceptions and practices that is anything but fixed and definitive.

I dwell on this since UNESCO has been an important agenda-setting body whose notions of heritage have been widely accepted by governments and heritage advocates across the world. Given its brief, it is unsurprising that UNESCO has focussed on the validation, celebration and subsequent promotion of branded heritage 'products.' But this is a one-sided approach: heritage contains much that that is inspirational for alerting us to error, tragedy and systematically damaging processes. These are, similarly, 'irreplaceable' elements of the past, aspects of the 
present and elements that persist, offering us significant lessons for the future. While sites such as the Hiroshima Peace Memorial and Auschwitz-Birkenau concentration camp are included in UNESCO's heritage listings, other notable disaster sites such as the locations of colonial massacres of Indigenous peoples or of industrial disaster such as Bhopal, India or Chernobyl, Ukraine, are not. As significantly, more dispersed events such as the diffusion of fluorocarbon gasses into the atmosphere by aerosol products in the 1970s and 1980s are equally unmarked as heritage phenomena.

Olsen and Pétursdóttir have provided a particularly insightful critique of affirmatory heritage that complements Smith's theorisation, emphasising how heritage activities are often conceived and approached as 'a kind of gardening work where good and sustainable pasts are nurtured at the expense of others,' reflecting what we might want to pass on to future generations (2016: 39). As they emphasise, what is left out is the fact that things are passed on whether we manage and care for them or not... independent of human control and selective remembering' (2016: 39-40). Drawing on this, they characterise the 'material obstinacy' of things and explore the idea of heritage as 'the "raw", unfiltered legacy passed on' (2016: 40). They also consider the role of memory and, in particular, of 'how memory is affected and enabled by both things' endurance and processes of ruination, and also with how the involuntary commemoration involved in living with an unruly heritage affects understandings of past, present and future' (2016: 40). They describe such 'unruly' heritages as 'sticky' and assert that the 'viscosity' of the material past 'complicates traditional notions related to historical succession and even chronology' (ibid.). This leads them to propose 'ruin ecology,' which they define as addressing:

how things in ruination affect our understanding of them, their material otherness, and the potential dimension of care embedded in this otherness. That is, how non-human companionships, alliances and hidden thingly affordances are invited as things become released from human usefulness and censorship, thus revealing other and unforeseen 'caring' potentials. For example, while ruined and abandoned buildings are marginalized in terms of the humanly useful... their increasingly more accessible facilities provide home and shelter for new non-human inhabitants: animals, birds, plants and funguses. Moreover, due to this care, and the new ruin ecology that emerges, these spaces also challenge heritage's commitment to an orderly and divided world, in which nature and culture, past and present, preservation and loss, are neatly kept apart. (2016: 41-42)

One aspect that Olsen and Pétursdóttir do not explore - but which could have provided a useful insight into the experience of exploring and/or living with 'sticky' heritage sites - is the phenomenon that Macaulay (1953) characterised as the 'pleasure of ruins' as things-in- themselves. As Macauley contends, ruins operate on their own terms rather than as simply decayed fragments of something else. She proposes ruination and processual decay as being as much a part of what might be termed the meaningful existence of things as their first, fresh incarnation. While knowledge of the Anthropocene's calamitous impact on the global environment and/or of the impact of settler colonisation of and construction on Indigenous lands necessarily complicates any such engagements with the relics of earlier human interventions, the former does not necessarily erase the latter but rather entangles the two.

\section{The Bay, The Mangroves}

Burns Bay (Figure 1), the site documented and considered in this article, is one that I inhabit, explore and contemplate on a daily basis. My engagement with it blurs research with everyday, incidental experience. I'm decidedly not disinterested in my site. Indeed, I'm fascinated by it and with trying to make sense of how my neighbours and I inhabit it. I am fortunate that the bay is surrounded by walking trails and vantage points that I can visit daily and fortunate to have a kayak tied up in the mangroves that I can use to paddle around the bay. I am also keenly aware of the history of decimation and dispossession of Indigenous peoples that underlies every aspect of the city. Equally, I am conscious of the impact of its industrial past and of the disruption caused by the subsequent construction of residential properties. In negotiating the messy nature of the site and of my research positioning within it, I was attracted by Toso, Spooner-Lockyer and Hetherington's account of their research on the 'ghostly' Saint Pierre River in Montreal in the first issue of Anthropocenes (2020). Their stated attempt to 'think about what it means to live in place in a more expansive and speculative way' by adopting a 'curious, experimental, open, adaptive, imaginative, responsive and responsible' approach has much to commend it. I was also attracted to their approach to analysis informed by the "multi-sensorial experience of walking' (Toso et al. 2020: 1). I have adopted similar approaches to my topic, perambulating on foot and by kayak in an attempt to understand Anthropocene heritage in a specific locale and the nature of the artefacts and experiences that might inspire more balanced and sustainable relations between various species and the environment in general. I am, thereby, involved in the type of 'patchwork ontologies' that Chandler and Pugh (2021: 4) identify, as I am located 'inside relations of interactive becoming rather than as a scientific observer manipulating or directing processes from "'above."' As they also add, in this 'flatter' ontology, the task is 'a more interactive one of responsively "staying with the trouble"' caused by 'relational disturbances and emergent effects' of the type identified by Haraway (2016).

Sydney Harbour comprises an extensive ria, a river valley system that was inundated by rising sea levels following the retreat of the last Ice Age, which reached their current levels around 7,000 years ago (Nunn and Reid 2015). Rias vary in extent and complexity. Sydney's is dendtritic, in that it has multiple arms. These arms 


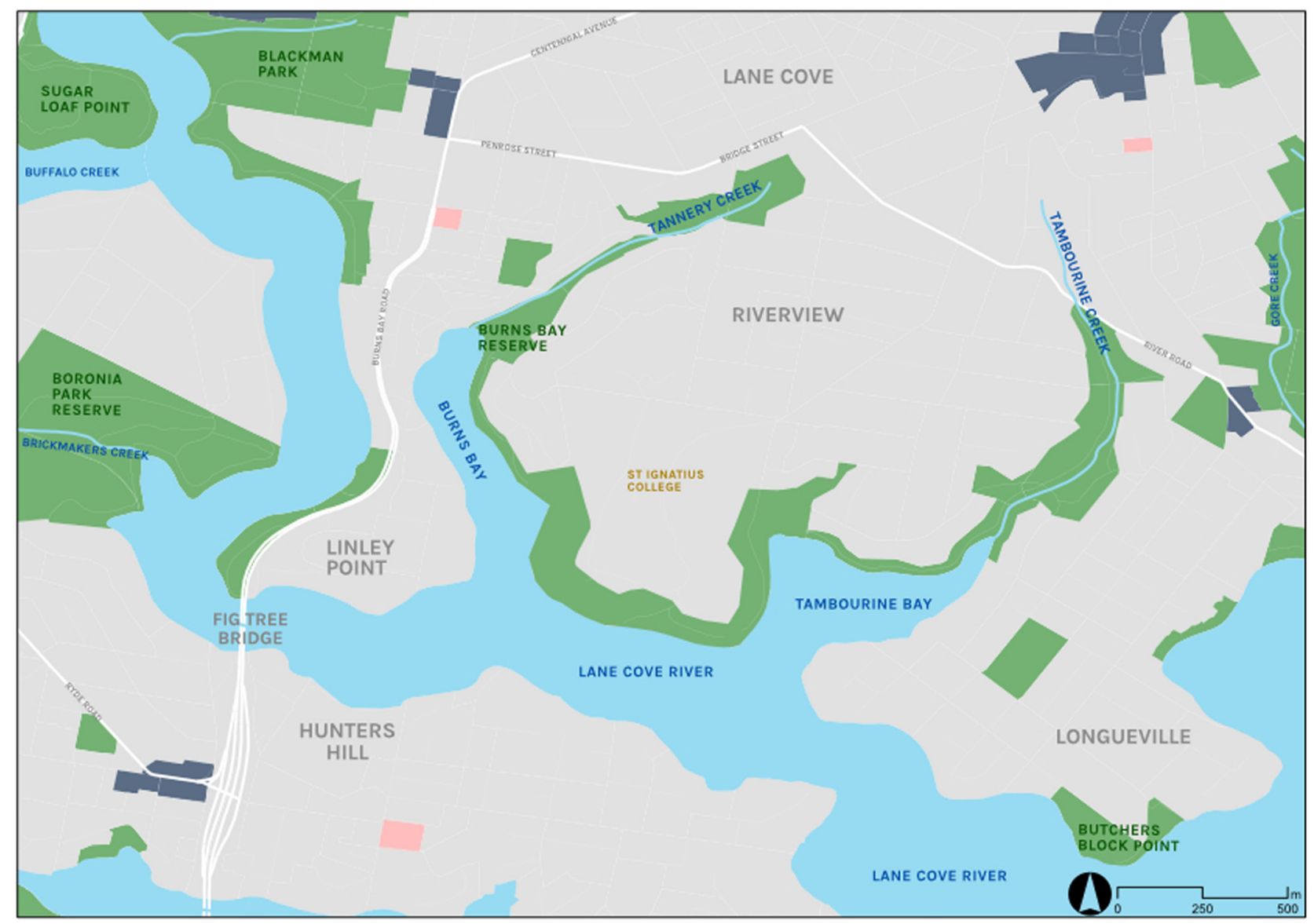

Figure 1: Map of Burns Bay and adjacent areas. Source: Vaughn Allan, 2021.

follow the routes of the rivers and smaller streams that flow into the Parramatta River, which commences in what is now central western metropolitan Sydney. During the period of initial European settlement there was a clustering of mangroves around the confluence of various freshwater streams and tributaries and the tidal reaches of the harbour. In this small but significant brackish interzone (Rogers, Mogensen, Davies et al. 2017), which rested on silt carried down to the coastline, two types of mangroves flourished: grey mangroves (Avicennia marina - a medium-sized tree that clustered the shoreline with its trunks meandering laterally and with its dense system of pneumatophoric roots breaking the surface at multiple points); and the smaller, shrub-like black mangroves (Aegiceras corniculatum), which commonly occur on the outer edges of mangrove areas. The mangrove isn't simply a plant that occurs around coasts, it creates - and is taken to denote - a particular ecosystem (Hogarth 1999; RiveraMonroy, Lee, Kristensen and Twilley 2017)). This ecosystem produces a substantial volume of discarded plant material that decays to provide food for various fish, shellfish, molluscs and insects and, in turn, attracts various bird species to consume these. In addition, these mangrove ecosystems, along with saltmarshes and seagrasses, are known for their significant carbon sequestration capacity, storing large amounts of organic carbon within the underlying sediments (Duarte, Middelburg and Caraco 2005). Around Sydney, these environments provide important nursery grounds for fish species such as flat-tail mullet (Gracimugil argenteus), which thronged the waters of Sydney Harbour at the time of European settlement, providing the area's Indigenous inhabitants with a bountiful food source. There was a particular cluster of such mangrove environments along Lane Cove River as it entered the Sydney Harbour, both in the bays on the north shore and along the shores of the river north-west of Lindley Point (Figure 1). These environments along a tidal stretch of river that the Cammeraygal clan referred to as Turrumburra (Farlow 2011) provided rich sources of marine protein for them. European settlement in the area commenced in the mid to late 1790s and was initially contested by clan groups who destroyed settlers' buildings and killed their animals before withdrawing into densely vegetated areas that colonists were reluctant to enter. As the nineteenth century progressed, growing colonial control over Sydney Harbour caused Indigenous groups to retreat from central Sydney in order to ensure their safety (Collins 1975) and to only transit through the Lane Cove area, with the latter practice ending around the turn of the twentieth century.

Human histories and experiences in mangrove areas have attracted the attention of a number of theorists, in particular, several working on Caribbean and Latin American cultures. Martiniquan novelist and theorist Édouard Glissant (1980) took up the motif of the mangrove as a geographically appropriate manifestation of the rhizome that was central to Deleuze and Guattari's seminal 1990 volume Mille Plateaux. Glissant notes that 
the mangrove is distinct for rooting upwards, emerging from below, an aspect he characterised as emblematic of Afro-Caribbean experience. Colombian anthropologist Arturo Escobar has also discussed entangled 'mangrove worlds' within his broader reflection on epistemologies of the global South, representing them as premised on a 'relational ontology' that is:

enacted minute by minute, day by day, through an infinite set of practices carried out by all kinds of beings and life forms, involving a complex organic and inorganic materiality of water, minerals, degrees of salinity, forms of energy (sun, tides, moon, relations of force), and so forth. There is a rhizome 'logic' to these entanglements, a 'logic' that is impossible to follow in any simple way, and very difficult to map and measure. (2016: 18)

While my study addresses aspects of mangrove experience in a very different context to both Glissant's and Escobar's reflections, it addresses an equally 'entangled' subject and also attempts to reflect the intricacy of such environments and ways of interacting with them.

In a manner that evokes Glissant's discussion of communities in Caribbean mangrove ecosystems as margin-dwellers, the difficulty of navigating the densely tangled mangrove systems in the northern bays also resulted in their being used by various fugitives and/or outlaws in the early 1800s, leading to the area's initial name, (variously) Murdering or Murderers' Bay, which was succeeded by its present designation, Burns Bay, in the 1830s. The cheapness of land in the area and access to streams led its marginality to ebb away as it came to be used for industrial purposes and in the 1860s two tanneries were established in the immediate hinterland of Burns Bay, on opposite banks of what is now known as Tannery Creek. Tanneries were then (and, indeed, continue to be) significant producers of waste products. As Frawley (2010) details, tree bark was an essential element of the tanning process in the nineteenth century, providing a cheap source of tannins. Various types of wattle (genus Acacia) provided highly suitable bark growing immediately adjacent to the Burns Bay tanneries and were harvested for that purpose. Tanning involved animal skins (usually from cattle, sheep or goats) being immersed in pools of tannin-infused water, with fats and hair being removed in the process and flushed away. The tanned hides were subsequently washed in freshwater streams and the surplus process water discarded. Along with the organic matter, discharged water high in tannins reduced the $\mathrm{pH}$ balance of the creek as it flowed into the bay. The construction of pools also disrupted the local landscape and led to fluid leaching into the soil, which changed its $\mathrm{pH}$ balance and dispersed organic material in it. To give some indication of the scale of this operation, the Ludowici Tanning plant operated 70 pits, processing up to 3,000 animal skins at any one time during its peak (Frawley 2010: 38). Local tannery operations continued through to the 1960s, with revised tannery techniques which included a significant use of chrome. This also dispersed into groundwater and into the creek and bay, where it persists in sediment and has entered the food chain. In this manner, the local situation is an instance of the general tendency described whereby 'past industrial practices contributed significantly to contamination of estuarine sediment' around Sydney Harbour (Birch, Lean and Gunns 2015: 314). Needless to say, I never fish in Burns Bay and the majority of those who do practice catch-andrelease, rather than fishing for food. Free from intensive fishing, but subject to heavy metal poisoning that causes various physical effects, the fish in the bay are plentiful and mullet (Mugil cephalus) often jump and splash as I slowly paddle through their waters. Similarly, the large and profuse clumps of Sydney rock oysters (Saccostrea glomerata) that I eagerly consume elsewhere remain undisturbed along the foreshore, quietly absorbing toxins.

In contemplating the chemical heritage around the Bay, I'm reminded of bigger events and chemical heritages, such as that of Chernobyl, where for thirty-five years humans have been mostly excluded, allowing native species to proliferate in a fallout zone that looks appealingly rewilded in video footage (Free Documentary - Nature 2021). Burns Bay is clearly no Chernobyl but the heritage effect is similar in type if not extent. The tannery buildings have been demolished and/or allowed to decay. They have been largely swallowed by the bush and exist now only as the ruins of early settler industry stumbled across by local bush walkers. These ruins can be read in various ways. For contemporary non-Indigenous Australians, they may have charm as signs of past pioneer inhabitation that helps ground new arrivals in the area. For Indigenous people and those sensitive to Indigenous history, they serve as starker monuments to the displacement of the traditional custodians of the land. For environmentalists, they act as a reminder of the extended duration and effects of the disruption of local habitats by settlers. For those who live around the Bay, they may be all (or none) of these.

Aside from the tanneries, whose history is largely hidden in the bush, in the water and in sediments, the local landscape manifests distinctive human interventions in terms of the nature of the shores of Burns Bay. In precolonial times the bay comprised an area of open tidal waters that transitioned to an extended area colonised by mangroves through which the creek flowed through from its point of origin, 1 kilometre inland. Dense vegetation crowded the foreshore beyond the boggy, mangrovecrowded areas, phasing from low saltmarsh ground cover to tall eucalypts on the mid and upper slopes. The construction of the tanneries not only involved clearing areas for pits and buildings but also the clearance of mangroves from the lower reaches of the creek to ensure that the small, low-draft vessels that carried materials to and from the tanneries and their main marketplace in the central Sydney could move through unobstructed. This clearance is now invisible as it has been superseded by larger clearances and modification of the bay's foreshore. This modification followed a model that was enacted elsewhere around Sydney Harbour in similarly configured locales. One of the most notable (and influential) examples of such modification was at Mosman, where the tidal area 
populated by mangroves was blocked off by a retaining wall and in-filled in the 1890s, with the area's creek being funnelled down a channel to the sea. The engineered site, a rare level area in an otherwise hilly suburb, became known as Reid Park and remains a popular recreation and sports amenity.

Like Reid Park, the flat, infilled area known as Burns Bay Reserve supports sporting activities and has a children's playground and, unusually, a heritage listed sewerage aqueduct that forms something of a gateway to the main park area from the foreshore (Figure 2). The reclaimed land leads to a path through an area of remnant bush that lines the upper half of Tannery Creek Valley. It's a pleasant environment that blends level parkland with steep, bush paths through tall trees with varied birdlife. The filling in of the former mangrove area has, however, depleted local biodiversity and removed a valuable fish breeding ground and wetland habitat. Tambourine Creek, which runs into Tambourine Bay, a short 20-minute walk to the south-east, is a notable example of a (largely undisturbed and now protected) mangrove-lined freshwater creek that flows through mudflats into the harbour (Figure 3). Kayaking



Figure 2: View of Burns Bay Reserve through one of the sewerage aqueduct arches (author's photo, December 2020).

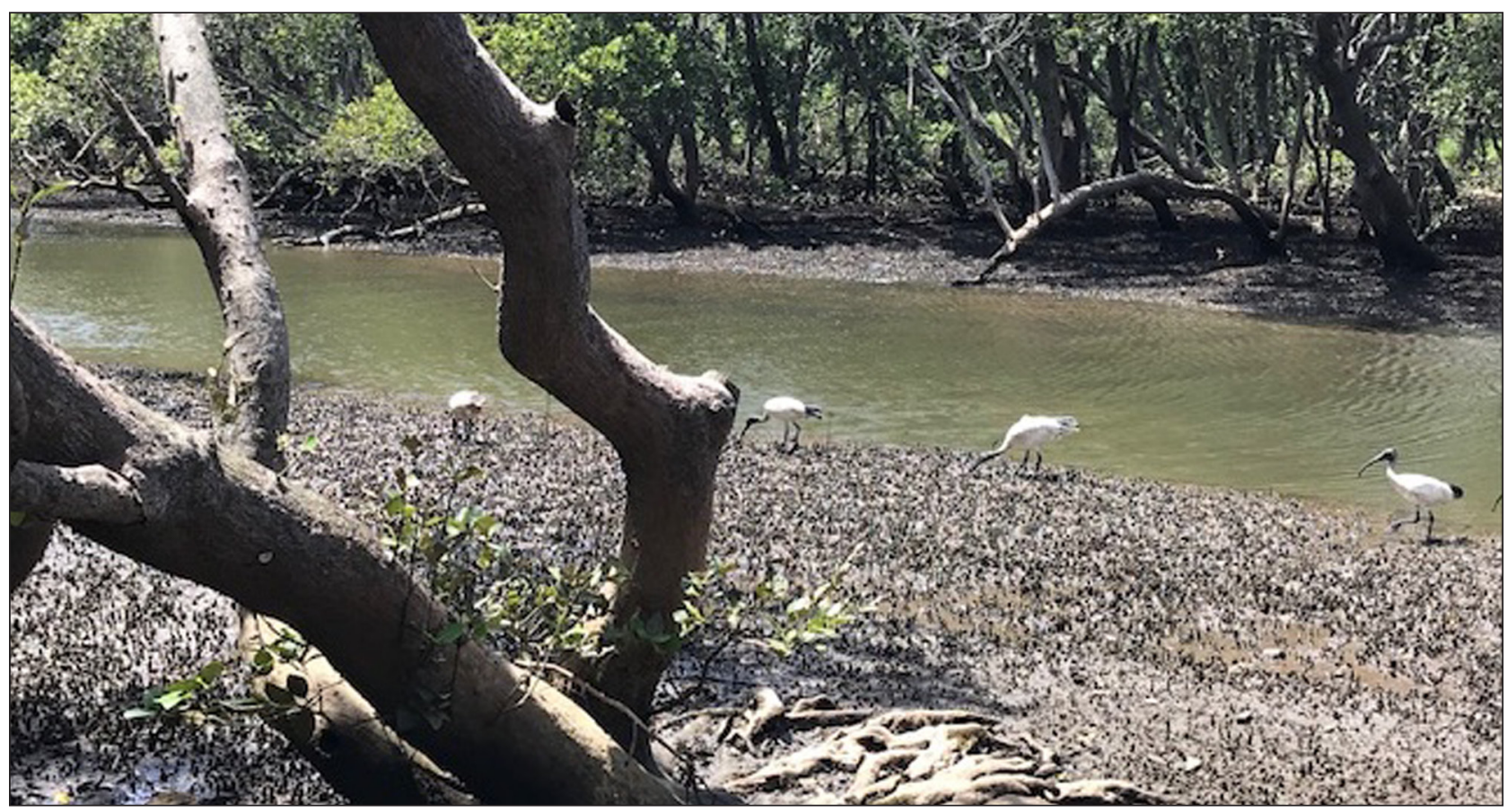

Figure 3: Lower reaches of Tambourine Creek (author's photo, December 2020). 
into its lower reaches at high tide you encounter vistas of wading birds such as white ibises (Threskiornis molucca) probing for shellfish as you move between the lower trunks of mangroves at the waterline and the clusters of oysters that adhere to them. It's a tangled, unruly, marshscape rich in biota and one that forms one of the few fish nurseries left on the harbour's northern shore. The contrast between the two throws the very manufactured and managed parkland of Burns Bay Reserve into sharp relief. The navigability of the lower reach of Tambourine Creek (for kayaks and other small craft) also contrasts to the impossibility of paddling up Tannery Creek. The engineering that created the drained park area guides the middle reaches of the creek into a paved passage that enters Burns Bay via a steep lip that is substantially raised above the level of the bay at low tide. Entering at high tide is equally problematic as the paved area has been raised and clogged at various points by the pneumatophoric roots of mangroves that have burst through the cracks between the lining stones (Figure 4). The clogged areas impede the flow of water and have allowed other mangroves to seed and terrestrial plants to gain purchase in small, elevated patches.

The mangroves show considerable agency in such spaces. Their growth patterns also illustrate the manner in which those involved in clearing the area underestimated the mangroves' power to regenerate in cleared waterways and foreshores. One of the mangroves' particular advantages in colonising waterfronts is that many species are viviparous, meaning that their seeds germinate on trees before falling off into the water. This allows the seed to float to new nooks and crannies on shorelines, in stone-lined watercourses or in shore walls. Once lodged in such places the seed can rapidly extrude roots that lock firmly into the material and grow. In many locations around Sydney Harbour, quite sizeable mangrove trees emerge from unlikely niches. In this way the mangrove can fairly rapidly recolonise the shorelines from which it was once removed. But such new plantings cannot easily recreate the larger mangrove ecosystems that develop around creeks and riverbank mudflats. They manifest the durability of the species but not the broader terrains they can generate given suitable conditions. With time and the withdrawal of human intervention, some related environments might develop but not any direct recreation of original ones.

Since the passing of the NSW government's Fisheries Management Act (1994), mangroves have received belated protection. Division 4 of the Act prohibits harm to mangroves (and 'certain other' types of vegetation such as seagrasses growing in tidal interzones). It became illegal for individuals or bodies to 'gather, cut, pull up, destroy, poison, dig up, remove, injure, prevent light from reaching or otherwise harm the marine vegetation, or any part of it.' While there is a utilitarian aspect to the Act, being addressed to maintaining habitat where fish might spawn (rather than the preserving particularity of mangroves), it nevertheless recognises the ecological value of the species and the habitats it forms, and mandates fines to act as a deterrent for clearing. If mangroves had a consciousness that could articulate such concepts, they might view European settler disruption of their ecosystem as representing a heritage of violence and wanton destruction, as opposed to their own, deeper heritage of ecosystem construction and maintenance. While it is mere anthropomorphic fancy to propose such a consciousness, the perspective is pertinent.

As I was working on the final draft of this paper, I was disappointed to read that a harbour ferry company had decided to discontinue its service between St. Ignatius School (situated on a bluff on the south-eastern corner of

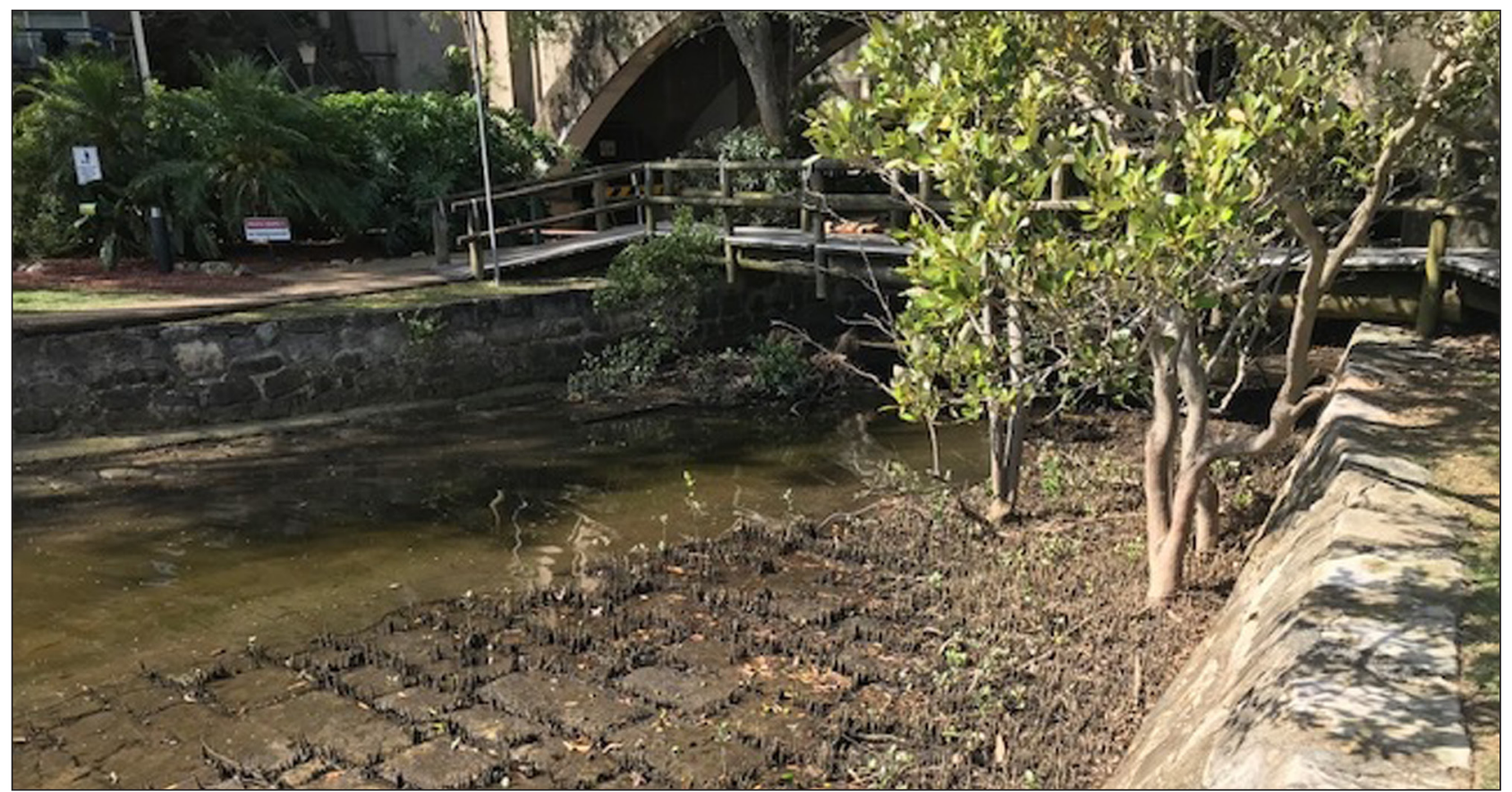

Figure 4: Paved mouth of Tannery Creek at low tide with entrenched mangroves (author's photo, December 2020). 
Burns Bay) and Circular Quay, in the heart of the city, a service I frequently use to commute into the university where I work. Unsettled by the news I set out in the kayak to paddle around to the School's waterfront. Down at the water level, a series of built structures at various stages in their histories of maintenance and usefulness pass by on my left. First up was the well-maintained school ferry jetty. As I paddle past, I wonder how long it will take for the jetty's timbers to decay and how quickly mangroves will gain purchase on the steps to the water at its far end. This probably won't happen - at least in the short term - as the prestigious school presumably wouldn't want such a sign of decay on its boundary, but it illustrates the unpredictable fate of waterfront facilities. Further along on the left, an abandoned stone jetty and the remnants of stone walls sit at the waterfront. I haven't managed to ascertain what purpose this structure originally served and when and why it was abandoned. I pause here, as I often do. It has a pleasant aspect, in the manner outlined by Macaulay (1953). It is constructed from the same sandstone that occurs in rocky outcrops all along the harbour and the native vegetation that has grown back around it appears to have embraced and reintegrated the material ruins into the bushland. Today, the broken-down jetty also has a welcome visitor, a healthy-looking adult pelican (Pelecanus conspicillatus), which I rarely see on my excursions. The pelican is perched neatly on a large cube of sandstone and appears entirely at home, surveying the river in front of it, completely disinterested in my presence as I gaze at it. It seems to have repossessed the structure.

There is a history of abandoned ferry routes in this area. In late 1800 s there were small pleasure gardens used for picnicking and dancing, one across the river from the School, at Fig Tree Farm, and one further upriver, charmingly named Fairyland. Before these there were also the patterns generated by Indigenous canoes that crisscrossed the harbour for various purposes. These abandoned routes left ripples, rather than ruins, and those ripples have long since subsided, but they had a presence nevertheless. They represent a lost heritage of waterborne experience, a ghostly affective field that the modernday kayaker traverses with little - if any - awareness as they move around Lane Cove and its bays. Similarly, the walking trails uses by indigenous clans are now broken and fragmented by urban development, with modern-day paths meandering scenically rather than offering more direct routes across the north shore of the Harbour. The experience of exploring the mangroves, coastal bush, hinterland paths and the odd (and often unexplained) ruins around Burns and Tambourine Bays can also lead to another aspect identified by Olsen and Pétursdóttir: a willingness to challenge 'heritage's commitment to an orderly and divided world, in which nature and culture, past and present, preservation and loss, are neatly kept apart' (2016: 42). Around the mangrove shores and adjacent bush, everything is entangled, the one penetrates the other. And below the material level, the local chemical heritage of the Anthropocene is also messy and largely unseen. It's known though, if only by proxy, by the lack of fishers and sizeable population of fish in the bay and by the oysters left to clump undisturbed around it.
In many ways, Burns Bay and its surrounds offer an inspirational and aesthetically pleasing locale for humans. In many others, it provides a more muted experience, offering salutary lessons for those who develop and pollute without short- or long-term concern for the environment. Its nonhuman actors, such as - in the account I offer here - mangroves, proceed to 'do what mangroves do' despite all that European settler culture has done to their environments. The mangrove, like all other species, constructs heritage in its own right, as well being a player in bigger heritage events and agendas. Retaining a sense of and respect for that history and for the lessons it offers can provide insight and inspiration for the future. Recognition of the 'material obstinacy' of the mangroves' dense systems of roots and branches and of the species' ability and impulse to recolonise waterfront areas can also help inspire affective alliances between humans and the nonhuman world, and allows the former to inhabit space with more appropriate levels of humility and respect. As Haraway concisely identifies:

There can be no environmental justice or ecological reworlding without multispecies environmental justice and that means nurturing and inventing multispecies - human and non-human - kindreds. Kin making requires taking the risk of becomingwith new kinds of person-making, generative and experimental categories of kindred, other sorts of 'we', other sorts of 'selves'... This kin making is crucial for imagining and crafting with each other still possible - barely possible - flourishing worlds, now and to come. (2018: 102)

These points are important since the Anthropocene can appear overwhelming. Hope is a rareand fragile commodity in world where carbon emissions, plastic permeation, species extinctions and other damaging phenomena are proving near impossible to reign in. But the heritage of construction and decay (resulting in what Olsen and Pétursdóttir [2016] refer to as 'ruin ecology') and various forms of deliberate human and spontaneous re-wilding of (once) developed locales provides perspective. Around Sydney Harbour these phenomena occur in a landscape that is inhabited - unlike the post-human scenarios posed by Weisman (2007) - allowing residents to perceive and commune with (the Anthropocene's version of) 'nature' as a processual heritage. This is crucial, as understanding that heritage and its multiple unfoldings is key to engaging with the juggernaut of the Anthropocene and to finding an experiential centre to ground ecological activism.

\section{Acknowledgements}

Thanks to Alison Rahn for relocating me to Burns Bay and to Greg McDonald for his useful feedback on an earlier draft on this article, to Vaughn Allan for providing the map and to the anonymous referees who gave insightful feedback on the first version of this paper.

\section{Competing Interests}

The author has no competing interests to declare. 


\section{Author Information}

Philip Hayward is an adjunct professor in the School of Communications at University of Technology, Sydney (Australia). He is editor of the open-access online journal Shima and has published extensively on island and maritime topics. Outside of academic work, he has been involved in a rainforest regeneration project in far north NSW (Australia) for over twenty years and is also a member of audiovisual ensemble The Moviolas.

\section{References}

Birch, G. F., Lean, J., \& Gunns, T. (2015). Growth and Decline of Shoreline Industry in Sydney Estuary (Australia) and Influence on Adjacent Estuarine Sediments. Environmental Monitoring and Assessment 187, 314. DOI: https://doi.org/10.1007/s10661-015-4481-y

Branagan, M. (2021). Collaborative Wilderness Preservation and the Franklin River Campaign. In R. Bartel, M. Branagan, F. Utley \& S. Harris (Eds.), Rethinking Wilderness and the Wild: Conflict, Conservation and Co-existence (pp. 50-65). Abingdon: Routledge. DOI: https://doi.org/10.4324/9780429299025-5

Chandler, D., \& Pugh, J. (2021). Anthropocene Islands: There Are Only Islands After the End of the World. Dialogues in Human Geography, 1-21. DOI: https:// doi.org/10.1177/2043820621997018

Collins, D. (1975). An Account of the English Colony in New South Wales. Sydney: AH \& AW Reed.

Deleuze, G., \& Guattari, F. (1980). Mille plateaux. Paris: Les Éditions de Minuit.

Duarte, C. M., Middelburg, J., \& Caraco, N. (2005). Major Role of Marine Vegetation on the Oceanic Carbon Cycle. Biogeosciences, 2(1), 1-8. DOI: https:// doi.org/10.5194/bg-2-1-2005

Escobar, A. (2016). Thinking-feeling with the Earth: Territorial Struggles and the Ontological Dimension of the Epistemologies of the South. Revista de Antropología Iberoamericana, 11(1), 11-32. DOI: https://doi.org/10.11156/aibr.110102e

Farlow, M. (2011). Lane Cove. Dictionary of Sydney. https://dictionaryofsydney.org/entry/lane_ cove\#: : text=Lane $\% 20$ Cove $\% 20$ is $\% 20$ a $\% 20$ suburb,and\%20beaches\%20of\%20Port\%20Jackson.

Frawley, J. (2010). Joseph Maiden and the National and Transnational Circulation of Wattle Acacia spp. Historical Records of Australian Science, 21(1), 35-54. DOI: https://doi.org/10.1071/HR09015

Free Documentary - Nature. (2021). Wildlife Takeover: How Animals Reclaimed Chernobyl (video) 50m 30s. Available at https://www.youtube.com/watch?v=XaU NhqnpiOE

Glissant, E. (1990). Poetics of Relation (trans. Wing, B.). Ann Arbor, MI: University of Michigan Press.

Godfrey-Smith, W. (1979). The Value of Wilderness. Environmental Ethics, 1(4), 309-319. DOI: https://doi. org/10.5840/enviroethics 19791426

Haraway, D. J. (2016). Staying With the Trouble: Making Kin in the Chthulucene. Durham, NC: Duke University Press. DOI: https://doi.org/10.2307/j.ctv11cw25q

Hogarth, P. (1999). The Biology of Mangroves and Seagrasses. Oxford: Oxford University Press.
Langton, M. (1996). What Do We Mean by Wilderness? Wilderness and Terra Nullius in Australian Art. The Sydney Papers, 8(1), 10-31.

Lee, E. (1996). Sacredness in the Tasmanian Wilderness World Heritage Area. Journal of World Heritage Studies, 8(1), 42-46.

Macaulay, R. (1953). Pleasure of Ruins. London: Weidenfeld and Nicolson.

McLaughlin, A. (1993). Regarding Nature: Industrialism, Environmentalism, and Deep Ecology. New York: State University of New York Press.

Monbiot, G. (2013). A Manifesto for Rewilding the World. The Guardian, 28 May. https://www.theguardian. com/commentisfree/2013/may/27/my-manifestorewilding-world

Morel, L., Barbe, L., Jung, V., Clement, B., Schnitzler, A., \& Ysnel, F. (2019). Passive Rewilding May (Also) Restore Phylogenetically Rich and Functionally Resilient Forest Plant Communities. Ecological Applications, 31(1). DOI: https://doi.org/10.1002/eap.2007

Naess, A. (1989). Ecology, Community and Lifestyle. Cambridge: Cambridge University Press. DOI: https:// doi.org/10.1017/CBO9780511525599

Nelson, M. P., \& Vucetich, J. A. (2013). Wilderness, Value of. In H. LaFollette (Ed.) The International Encyclopedia of Ethics. (pp. 1-9). Hoboken, NJ: Wiley-Blackwell. DOI: https://doi.org/10.1002/9781444367072.wbiee645

New South Wales Government. (1994). Fisheries Management Act 1994, No 38. https://www. legislation.nsw.gov.au/view/html/inforce/current/ act-1994-038\#sec.204

Nunn, P. D., \& Reid, N. J. (2015). Aboriginal Memories of Inundation of the Australian Coast Dating from More Than 7000 Years Ago. Australian Geographer, 47(1), 11-47. DOI: https://doi.org/10.1080/00049182.2015 .1077539

Olsen, B., \& Pétursdóttir, P. (2016). Unruly Heritage: Tracing Legacies in the Anthropocene. Arkceologisk Forum 35, 38-46.

Rivera-Monroy, V. H., Lee, S. Y., Kristensen, E., \& Twilley, R. R. (Eds.) (2017). Mangrove Ecosystems: A Global Biogeographic Perspective - Structure, Function, and Services. Berlin: Springer. DOI: https://doi. org/10.1007/978-3-319-62206-4

Rogers, K., Mogensen, L., Davies, P., et al. (2017). Mangrove and Saltmarsh Threat Analysis in a Large City: Opportunities and Challenges for Management. NSW Coastal Conference paper. https://www.coastalconference. com/2017/papers2017/Laura\%20Mogensen 1.pdf

Shaw, M. (1996). The History of the Battle to Save Kelly's Bush and the Green Ban Movement in the Early 1970 s. Sydney: Buckleys.

Smith, L. (2006). Uses of Heritage. London: Routledge. DOI: https://doi.org/10.4324/9780203602263

Toso, T., Spooner-Lockyer, K., \& Hetherington, K. (2020). Walking with a Ghost River: Unsettling Place in the Anthropocene. Anthropocenes - Human, Inhuman, Posthuman, 1(1), 3. DOI: https://doi.org/10.16997/ ahip.6

Weisman, A. (2007). The world without us. New York: Saint Martin's Press. 
How to cite this article: Hayward, P. (2021). Entangled in the Mangroves: Negotiating Anthropocene Heritage in the Terrestrial/ Marine Interzone of an Iconic Harbour City. Anthropocenes - Human, Inhuman, Posthuman, 2(1): 9. DOI: https://doi.org/10.16997/ ahip.926

Published: 09 August 2021

Copyright: ( 2021 The Author(s). This is an open-access article distributed under the terms of the Creative Commons Attribution 4.0 International License (CC-BY 4.0), which permits unrestricted use, distribution, and reproduction in any medium, provided the original author and source are credited. See http://creativecommons.org/licenses/by/4.0/.

W Anthropocenes - Human, Inhuman, Posthuman is a peer-reviewed open access journal published by University of Westminster Press. 